\title{
A LIFE CYCLE ASSESSMENT OF ENERGY FROM WASTE AND RECYCLING IN A POST-CARBON FUTURE
}

\author{
Stephen John Burnley * \\ School of Engineering and Innovation, The Open University, Walton Hall, Milton Keynes, MK7 6AA, United Kingdom
}

Article Info:

Received:

27 November 2018

Revised:

8 February 2019

Accepted:

22 February 2019

Available online:

31 March 2019

Keywords:

Life cycle assessment

Environmental impact

Low-carbon future

Energy

\begin{abstract}
Life cycle assessment was used to investigate the environmental impacts and benefits of managing residual municipal solid waste, waste newspapers and organic waste for two energy supply scenarios. In the first scenario, the electricity generated by energy from waste and landfill gas combustion displaces grid electricity generated from natural gas. The electricity and process heat used in the recycling and primary material production processes are also generated from gas. In the second scenario, wind power is the marginal electricity source displaced by energy from waste (EfW) and landfill gas use and wind and biomass are used to provide process electricity and heat respectively. The results show that, under both energy supply scenarios, treating the residual non-recyclable municipal solid waste in EfW facilities is preferable to landfill. Comparing the recycling of waste paper with EfW shows that neither option can be regarded as the better environment option and this is the case regardless of the energy supply scenario. The environmental burdens of treating organic waste by $\mathrm{EfW}$ increase with a move to wind power and, in this case, the results suggest that composting has environmental advantages over EfW. Normalising the LCA results demonstrates that waste management represents a low proportion $(-1.5 \%$ to $1.5 \%)$ of an individual's contribution to their overall LCA impacts.
\end{abstract}

\section{INTRODUCTION}

The European Union's (EU) member states and many other developed countries have made great progress in improving the sustainability of their waste management systems with the adoption of measures designed to implement the Waste Hierarchy. The hierarchy lists the options for dealing with waste in decreasing order of preference. There are several versions of the hierarchy, but they all specify waste reduction followed by recycling and energy recovery with landfill to be treated as a last resort. The concept of the "Circular Economy" develops this further by encouraging product designers, manufacturers and suppliers to work towards eliminating waste altogether by using materials and designing products that can be re-used and recycled. The Circular Economy package is being implemented in all EU member states and includes a series of measures on general and specific waste streams and introduces targets including a minimum municipal waste recycling rate of $65 \%$ and a maximum municipal waste landfill rate of $10 \%$ by 2035 (European Commission, undated).

As well as contributing to the circular economy targets, it is widely accepted that diverting wastes from landfill through reduction, recycling and energy from waste (EfW) achieves many benefits. It can be argued that landfills are inherently unsustainable because it may take many generations for a degradable waste landfill to become stable and no longer pose a risk to public health or the wider environment (Kjeldsen et al., 2002; Burnley and Boardman, 2017). Landfilling recyclable and recoverable materials also removes valuable resources from the economic cycle. Other benefits of avoiding landfill are the reduction in the formation and escape of landfill gas and leachate. Recovering energy and recycling materials from waste also reduces the consumption of primary resources which are often non-renewable. Manufacturing materials from recyclate is often far less energy intensive than manufacturing that begins with raw materials. For example, the climate change impact of making aluminium cans from recycled aluminium is $95 \%$ less than manufacturing cans from raw materials, principally due to the reduction in fossil fuel combustion (Paraskevas et al., 2015). Finally, many developed countries impose taxes on landfill and restrict the types and quantities of waste that can be landfilled.

Life Cycle Assessment (LCA) is an environmental management technique that allows the environmental impacts and benefits of providing and using goods and services to 
be determined. LCA studies are generally based on the following stages.

- Setting the goal and scope of the study.

- Compilation of inventories of the materials and resources consumed and environmental emissions released during an activity (reductions in emissions through recycling and energy from waste are included here).

- Classification of all the emissions into standard categories such as global warming potential (GWP), acidification and human toxicity.

- Characterisation of the emissions in each category to allow the individual impact of each emission to be summed (for example $1 \mathrm{~kg}$ of methane emitted is equivalent to $25 \mathrm{~kg}$ of $\mathrm{CO}_{2}$ ).

- Interpretation and discussion of the results.

Many computer-based tools are available to carry out LCA calculations and there is an international standard for carrying out and reporting LCAs (BS EN ISO, 2006). Additional guidance on bio-based products (such as paper) is available in a European standard (BS EN, 2015). Several LCA tools have been developed aimed specifically at waste management processes including Denmark's EASETECH, the UK's Waste and Resources Assessment Tool for the Environment (WRATE) and the USEPA's Decision Support Tool (DST). The literature on waste management LCAs is extensive (for example Villanueva and Wenzel, 2007; Bates, 2009; Christensen et al., 2009; Finnveden et al., 2009; Michaud et al., 2010; Schott et al., 2016). Generally, the results of waste management LCAs suggest that materials recycling is environmentally beneficial and that a well operated EfW facility has distinct environmental advantages over landfill. The benefit of EfW over landfill from the climate change perspective is particularly strong when the energy produced by the EfW displaces power and/or heat produced from a carbon-intensive source such as coal or gas. In recent years, improvements in the thermal efficiency of EfW and improved aluminium and steel recovery rates from the EfW bottom ash have increased the environmental advantages of EfW compared with landfill.

International agreements to tackle climate change are leading to reductions in the carbon intensity of power and heat production in many countries. For example, the EU's average electrical power carbon intensity fell from 431 to 276 t CO$_{2}$ equivalent per GWh over the period 1990-2014 (European Environment Agency, 2018). Some member states are achieving much lower levels such as France at $34 \mathrm{t} \mathrm{GWh}-1$ in 2014. The overall downward trend is expected to continue due to measures such as the UK's commitment to close its coal fired power stations by 2025 (unless they incorporate carbon capture and storage technology) (DBEIS, 2018). As countries continue to reduce their use of fossil fuels, the environmental benefits of EfW and materials recycling will change.

This paper investigates whether moving to low-carbon power and heat sources will change the environmental impacts and benefits from managing municipal waste and its components. An LCA study was carried out to de- termine whether a move to low-carbon energy supplies would affect the optimum choice of waste management options. This study compares the environmental impact of:

- treating non-recyclable residual municipal solid waste (rMSW) by EfW and landfill;

- managing waste newspapers by recycling and EfW;

- managing organic waste (kitchen and garden waste) by composting and EfW.

The EfW is typical of current UK plant, producing power at a net thermal efficiency of $25 \%$, but not recovering any thermal energy.

Two energy supply scenarios were considered. In the first, it was assumed that any electricity generated by EfW or landfill gas use displaces an equivalent quantity of electricity generated from burning natural gas in a combined cycle gas turbine (CCGT) system. In the second scenario, this "marginal" electricity source was offshore wind power. Similarly, the first scenario assumed that the electricity and process heat used by manufacturing and recycling processes were generated by natural gas and, in the second scenario, by wind power and biomass fuel (wood) respectively.

\subsection{Abbreviations}

CCGT Combined cycle gas turbine - a gas fired electricity generation process where a gas turbine is followed by a steam-raising boiler.

CML A database of characterisation factors used in the classification and characterisation stages of an LCA.

DST Decision Support Tool - an online tool for performing waste management LCAs developed by the United States Environmental Protection Agency (USEPA)

Easetech Environmental Assessment System for Environmental TECHnologies - a software tool for performing LCAs of waste management systems and processes developed by the Technical University of Denmark (DTU).

EfW Energy from Waste - a waste management process where waste is burned under tightly-controlled conditions using the heat released to generate electrical energy and/or heat for process use or space heating.

GWP Global Warming Potential - A means of comparing the impact of different substances on global climate change relative to the impact of carbon dioxide $\left(\mathrm{CO}_{2}\right)$

LCA Life Cycle Assessment - a systematic quantitative assessment of the environmental impacts of a product or system.

rMSW Residual municipal solid waste. The waste generated by households and similar business premises once the recyclable and compostable fractions have been removed by the producer at source. 
SimaPro A general-purpose LCA software system widely used for LCA assessments of processes, goods and services.

SCR Selective catalytic reduction - a process for reducing the NOx emissions from combustion gases using a catalytic reactor.

SNCR Selective non-catalytic reduction - a process for reducing the NOx emissions from combustion gases by injecting ammonia or urea into the furnace.

WRATE Waste and Resources Assessment Tool for the Environment - a waste management LCA tool developed by the Environment Agency for England

\section{METHODS}

The goal of this LCA study is to compare the life cycle burdens of managing rMSW, waste newsprint and organic waste when the electricity and process heat used during processing and generated (or saved by) the waste management process are generated from fossil and renewable sources. The system boundary is illustrated in Figure 1.

In each example, the functional unit is defined as "the management of one tonne of the waste material under consideration".

The environmental burdens were categorised and then characterised using the ecoinvent database of life cycle inventories for common manufacturing and energy supply processes provided with SimaPro version 8 (Frischknecht et al., 2005). The impact categories used were a sub-set of six of the CML 2001 (Guinée, 2002) categories considered by the UK's Department for Environment Food and Rural Affairs (Defra) to be most relevant for LCAs related to municipal waste management. CML factors were also used to normalise the impacts; a process that allows the characterised impacts in each category to be compared with the annual amounts produced by the average European citizen. The categories and characterisation factors are listed in Table 1.

The composition of the rMSW was taken from Defra (2009) and the environmental capital and operating burdens of the processes were taken from the ecoinvent database or from WRATE's database which was compiled after an extensive data-gathering programme undertaken among the UK's waste processing plant operators and manufacturers. These sources are summarised in Table 2. It should be noted that many inventories in ecoinvent and WRATE are based on anonymous sources; when this is the case, no specific reference is given, but in all cases, the data were subjected to peer-review while compiling the inventories. In considering the low-carbon energy scenario, the inventories were modified by replacing fossil heat and power with wind power and biomass-derived heat respectively.

\section{RESULTS AND DISCUSSION}

A summary of the main material and energy inputs to and outputs from the waste management processes is shown in the first five columns of Table 3.

Detailed life cycle inventories of all significant pollutant emissions from the processes are included in the supplementary tables.

TABLE 1: Overview of sites and samples used.

\begin{tabular}{l|c}
\hline Impact category & Characterised as \\
\hline Global warming potential (GWP) & $\mathrm{kg} \mathrm{CO}_{2}-\mathrm{eq}$ \\
\hline Resource depletion & $\mathrm{kg} \mathrm{Sb}-\mathrm{eq}$ \\
\hline Acidification & $\mathrm{kg} \mathrm{SO}_{2}-\mathrm{eq}$ \\
\hline Eutrophication & $\mathrm{kg} \mathrm{PO}_{4}-\mathrm{eq}$ \\
\hline Human toxicity & $\mathrm{kg} \mathrm{1,4DB-eq}$ \\
\hline Aquatic ecotoxicity & $\mathrm{kg} \mathrm{1,4DB-eq}$ \\
\hline
\end{tabular}

Background system

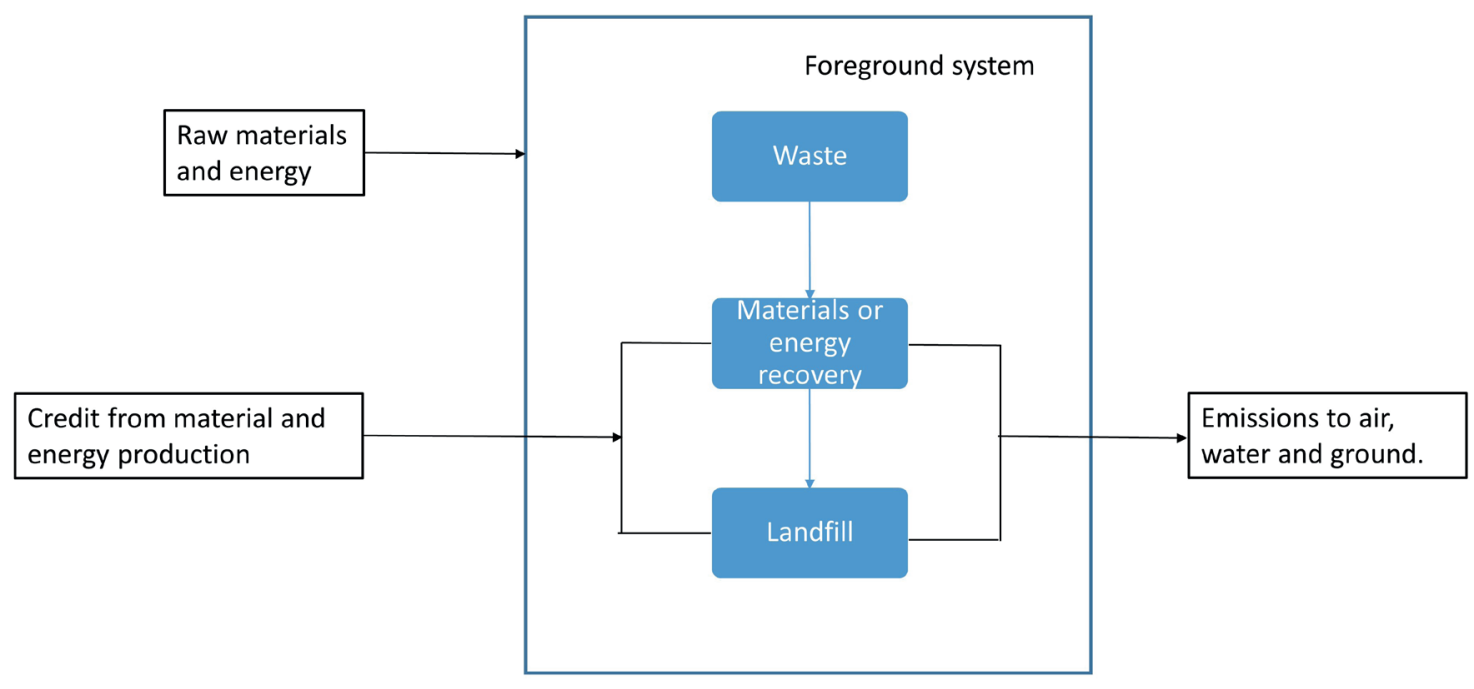

FIGURE 1: LCA system boundary. 
TABLE 2: Sources of information used.

\begin{tabular}{|c|c|}
\hline Data & Source \\
\hline General product inventories & ecoinvent (Undated) \\
\hline $\begin{array}{l}\text { Impact categories and normalisation } \\
\text { factors }\end{array}$ & CML 2001 \\
\hline rMSW waste composition & Defra (2009) \\
\hline EfW plant capital burdens & WRATE \\
\hline EfW process emissions & WRATE \\
\hline Landfill emissions & ELCD (2010) \\
\hline Composting plant emissions & WRATE \\
\hline Gas-fired power generation & ecoinvent (undated) \\
\hline Offshore wind power generation & ecoinvent (undated) \\
\hline Biomass process heat generation & ecoinvent (undated) \\
\hline Paper manufacture & Hischier (2007) \\
\hline Aluminium manufacture & Classen et al (2009) \\
\hline Benefits of compost use & WRATE \\
\hline
\end{tabular}

Note: WRATE data were obtained by the Environment Agency during the production of WRATE. The WRATE tool includes the detailed inventories, sources of external data used and an assessment of the reliability of the data.

\subsection{Power generation}

Table 4 and Figure 2 display the environmental burdens associated with the generation of $1 \mathrm{kWh}$ of electrical energy using coal, natural gas, rMSW and offshore wind. In Figure 2 the results are expressed as a percentage of the source presenting the highest level of emissions.

These results confirm that coal is the most polluting of the four alternatives and, with the exception of the two tox- icity categories, wind power is the least polluting option. The, possibly counter-intuitive, results for wind power toxicity are accounted for by emissions during the manufacture of the chromium steels used in the structure of the turbines. The most polluting discharges being hexavalent chromium to water in the case of human toxicity and nickel and cobalt discharges to water for aquatic ecotoxicity. It should be noted that life cycle data on wind turbine manufacture and use is limited and that the LCA inventory used by SimaPro dates from 2007 and refers to a single Danish installation. Until operational experience produces reliable estimates of the operational lifetime of turbines and the fate of the end of life components, life cycle inventories of such systems should be treated with caution. One later peer-reviewed LCA inventory (Razdan and Garrett, 2015) assumed a 20 year life and that $92 \%$ of the steel, aluminium and copper is recycled at the end of the life, but added that no present generation turbines have reached the end of their life yet and 20 years could be an under-estimate. Recently, Ozoemena et al. (2018), suggested that the human and aquatic ecotoxicity impacts of wind power could be reduced by up to $40 \%$ by making increased use of carbon fibres in the tower structure and using permanent magnets in the alternators.

The polluting nature of coal means that, in regions where large quantities of coal are still used for power generation, this is the source that should be replaced by EfW, at least from the environmental perspective. However, a number of countries are reducing coal use with the ultimate aim of complete elimination, so coal should no longer be treated as the marginal source in these ar-

TABLE 3: Summary of material and energy flows and LCA burdens (1000 kg input).

\begin{tabular}{|c|c|c|c|c|c|c|c|c|c|c|}
\hline \multirow[t]{2}{*}{ Process } & \multirow{2}{*}{$\begin{array}{c}\text { Energy } \\
\text { dis- } \\
\text { placed }\end{array}$} & \multirow{2}{*}{$\begin{array}{c}\text { Useful } \\
\text { energy } \\
\text { exported }\end{array}$} & \multirow{2}{*}{$\begin{array}{l}\text { Materials } \\
\text { recycled }\end{array}$} & \multirow{2}{*}{$\begin{array}{l}\text { Residue } \\
\text { to landfill }\end{array}$} & \multicolumn{6}{|c|}{ LCA burdens } \\
\hline & & & & & $\begin{array}{c}\text { GWP } \\
\mathrm{kg} \mathrm{CO}_{2} \text {-eq }\end{array}$ & $\begin{array}{l}\text { Resource } \\
\text { depletion } \\
\text { kg Sb-eq }\end{array}$ & $\begin{array}{l}\text { Acidifica- } \\
\text { tion } \\
\mathrm{kg} \mathrm{SO}_{2} \text {-eq }\end{array}$ & $\begin{array}{c}\text { Eutrophica- } \\
\text { tion } \\
\mathrm{kg} \mathrm{PO}_{4} \text {-eq }\end{array}$ & $\begin{array}{c}\text { Human } \\
\text { toxicity } \\
\mathrm{kg} 1,4 \mathrm{DB}-\mathrm{eq}\end{array}$ & $\begin{array}{c}\text { Aquatic } \\
\text { ecotoxicity } \\
\text { kg 1,4DB-eq }\end{array}$ \\
\hline \multicolumn{11}{|l|}{ rSMW } \\
\hline Landfill & $\mathrm{F}$ & $345 \mathrm{MJ}$ & - & $1000 \mathrm{~kg}$ & 440 & 0.14 & 0.29 & 2.4 & -8.1 & -0.11 \\
\hline EfW & $\mathrm{F}$ & $2020 \mathrm{MJ}$ & - & 290 kg & 23 & -2.2 & 0.47 & 0.11 & -28 & 1.5 \\
\hline $\mathrm{EfW}+\mathrm{Al}$ & $\mathrm{F}$ & $2020 \mathrm{MJ}$ & $6.5 \mathrm{~kg}$ & $284 \mathrm{~kg}$ & -52 & -2.6 & 0.12 & -0.0052 & -390 & -48 \\
\hline Landfill & $\mathrm{R}$ & $345 \mathrm{MJ}$ & - & $1000 \mathrm{~kg}$ & 490 & 0.54 & 0.33 & 2.4 & 7.7 & 1.5 \\
\hline EfW & $\mathrm{R}$ & $2020 \mathrm{MJ}$ & - & $290 \mathrm{~kg}$ & 290 & 0.061 & 0.58 & 0.14 & -3.4 & -5.9 \\
\hline $\mathrm{EfW}+\mathrm{Al}$ & $\mathrm{R}$ & 2020 MJ & $6.5 \mathrm{~kg}$ & $284 \mathrm{~kg}$ & 250 & -0.053 & 0.43 & 0.11 & -350 & -40 \\
\hline \multicolumn{11}{|l|}{ Newsprint } \\
\hline EfW & $\mathrm{F}$ & $2950 \mathrm{MJ}$ & - & 30 kg & -360 & -3.1 & 0.44 & 0.10 & -51 & 1.8 \\
\hline Recycling & $\mathrm{F}$ & - & 1000 & - & 180 & 1.4 & -1.2 & -0.40 & -26 & -24 \\
\hline EfW & $\mathrm{R}$ & $2950 \mathrm{MJ}$ & - & $30 \mathrm{~kg}$ & 14 & 0.048 & 0.55 & 0.13 & -4.2 & -5.8 \\
\hline Recycling & $\mathrm{R}$ & - & 1000 & - & 35 & -0.22 & -0.37 & 0.60 & 59 & 92 \\
\hline \multicolumn{11}{|l|}{ Organic waste } \\
\hline EfW & $\mathrm{F}$ & $937 \mathrm{MJ}$ & - & $100 \mathrm{~kg}$ & -92 & -0.86 & 0.59 & 0.15 & 7.2 & 2.8 \\
\hline EfW & $\mathrm{R}$ & $937 \mathrm{MJ}$ & - & $100 \mathrm{~kg}$ & 18 & 0.094 & 0.56 & 0.14 & 15 & -1.4 \\
\hline Composting & See text & - & 320 kg & - & 6.8 & 0.069 & 0.17 & 0.14 & 19 & 3.5 \\
\hline
\end{tabular}

$F=$ Gas-derived electricity and gas/oil process heat

$R=$ Wind power and biomass process heat 
TABLE 4: Environmental burdens of generating $1 \mathrm{kWh}$ of electrical energy based on the results of the characterisation stage of the LCA.

\begin{tabular}{|c|c|c|c|c|c|c|}
\hline & $\begin{array}{c}\text { GWP } \\
\mathrm{kg} \mathrm{CO}_{2} \text {-eq }\end{array}$ & $\begin{array}{c}\text { Resourcedepletion } \\
\text { kg Sb-eq }\end{array}$ & $\begin{array}{l}\text { Acidification } \\
\mathrm{kg} \mathrm{SO}_{2}-\mathrm{eq}\end{array}$ & $\begin{array}{c}\text { Eutrophication } \\
\mathrm{kg} \mathrm{PO}_{4}-\mathrm{eq}\end{array}$ & $\begin{array}{c}\text { Human toxicity } \\
\text { kg 1,4DB-eq }\end{array}$ & $\begin{array}{c}\text { Aquatic ecotoxicity } \\
\text { kg 1,4DB-eq }\end{array}$ \\
\hline Wind & 0.014 & $9.65 \times 10^{-5}$ & $6.15 \times 10^{-5}$ & $3.05 \times 10^{-5}$ & 0.061 & 0.015 \\
\hline Natural gas & 0.48 & 0.0041 & 0.00026 & $7.37 \times 10^{-5}$ & 0.10 & 0.0018 \\
\hline Coal & 1.1 & 0.0083 & 0.0028 & 0.0025 & 0.28 & 0.38 \\
\hline rMSW & 0.52 & 0.00020 & 0.0011 & 0.00027 & 0.055 & 0.0044 \\
\hline
\end{tabular}

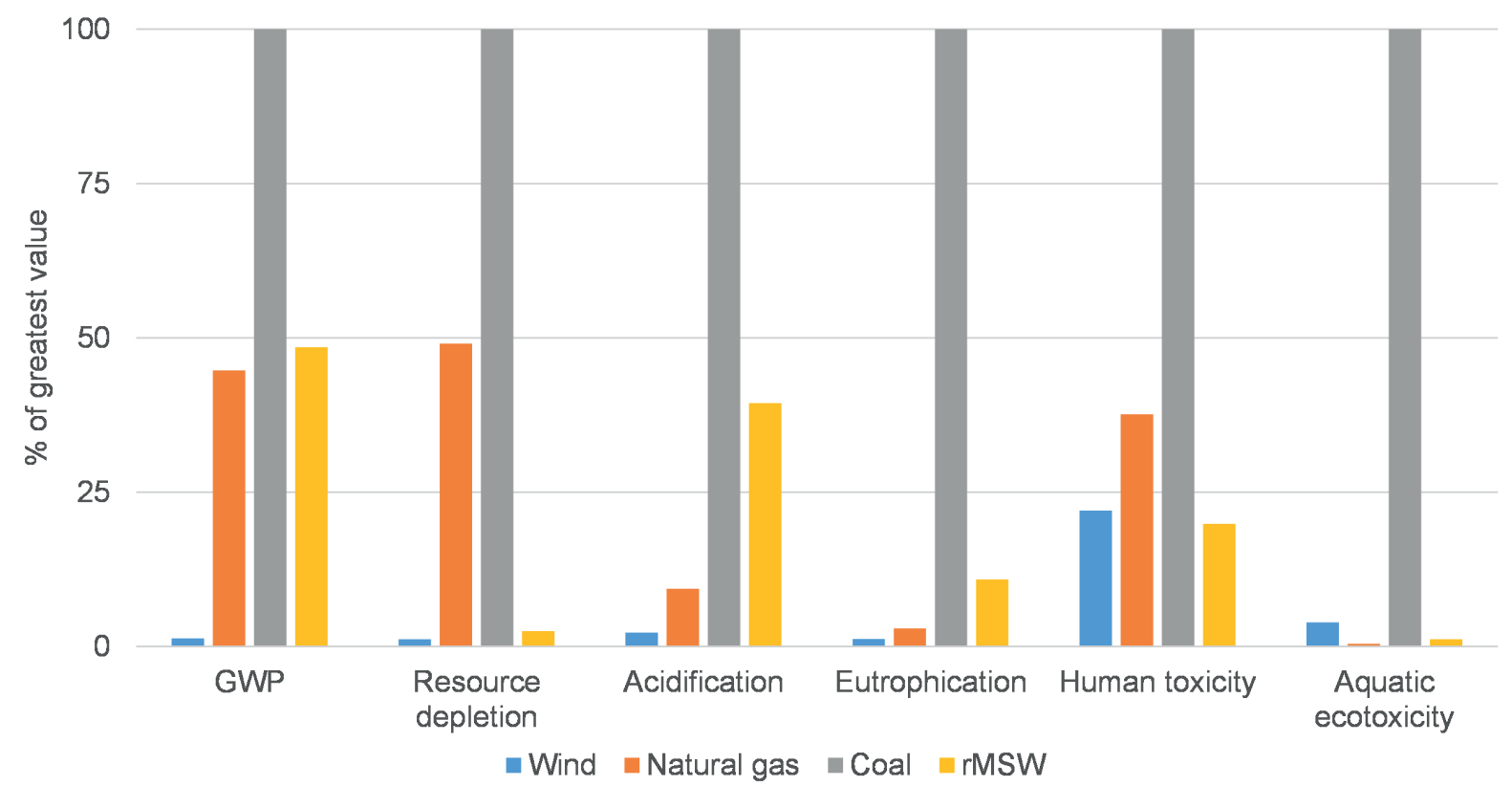

FIGURE 2: Environmental burdens of generating $1 \mathrm{kWh}$ of electrical energy.

eas. Taking the UK as an example, where coal supplied $7 \%$ of the nation's electricity in 2017 , the most realistic assumption is to consider that EfW displaces gas-derived power at present. In the long term, when there has been a substantial reduction in carbon-based energy production, renewable energy, or a combination of nuclear and renewable energies, will be displaced by EfW and the appropriate combination should be used as the marginal source in LCAs relating to the future. This research uses wind power as an example and, while this is perhaps an unrealistic scenario, it illustrates the issues relating to a low-carbon future and avoids the complexity of comparing the impacts for a range of low-carbon electricity sources. A wider range of sources will be considered in future phases of this research.

Comparing the impacts of wind and EfW in Table 4 and Figure 2 shows that, in a carbon-free future, replacing wind power with EfW would present environmental disadvantages in terms of global warming, resource depletion, acidification and eutrophication, there would be no significant difference with respect to human toxicity but the move to EfW would be advantageous when considering aquatic ecotoxicity impacts.

These overall preliminary findings are not surprising, and suggest that the environmental benefits from EfW will be reduced as power generation moves to renewable sources in the future. However, this does not mean that
EfW of rMSW should be discontinued in the future for two important reasons:

- EfW still presents environmental benefits when compared to the alternative option of landfilling (as shown below);

- EfW represents a reliable and continuous source of electricity and is not reliant on the presence of wind or sunlight so it could have value as a baseload supply.

\subsection{LCA Comparisons of EfW and landfill of rMSW}

The environmental advantages of EfW over landfill for non-recyclable rMSW have been demonstrated in many LCAs (for example Maalouf and El-Fadel, 2018; Hadzic et al., 2018) for the current energy supply situation. Recovering and recycling aluminium from the EfW ash accounts for a significant proportion of the environmental benefits of EfW (Burnley et al., 2015) and is becoming common practice. Therefore, it was considered necessary to consider the impacts of aluminium production and recycling under the two energy supply scenarios. The LCA impacts of aluminium manufacture from raw materials and recycling were determined are shown in Table 5 (after Classen et al., 2009). This table confirms that recycling aluminium has major environmental advantages over primary production in all impact categories. Furthermore, these advantages 
are still achieved with a move from gas to wind power and renewable heat.

The right hand columns of Table 3 present a comparison of the life cycle burdens of the waste management options considered. When gas-fired power is displaced and aluminium is not recovered, EfW provides overall environmental benefits (negative emissions) for resource depletion and human toxicity. For GWP and eutrophication, EfW does have an adverse impact, but this is lower than if the waste was landfilled. In contrast, for acidification and aquatic ecotoxicity, EfW results in higher environmental burdens than landfill. The principal causes of these impacts are nitrogen oxide emissions to air from the EfW process and acenaphthylene (a poly aromatic hydrocarbon) emissions to air from the manufacture of the plastics used in the EfW plant respectively. When the benefits from aluminium recycling are included, the impact reductions shown in Table 4 are realised and EfW now provides overall benefits in each of the categories apart from acidification and is preferable to landfill in all impact categories.

With the move to wind-derived electricity, the overall picture is similar in that EfW has overall benefits in some categories and is preferable to landfill in all categories. When aluminium is not recovered, $\mathrm{EfW}$ is now preferable to landfill in all categories apart from acidification (again due to nitrogen oxides emissions). The greater advantage now seen in the aquatic ecotoxicity category is due to the better performance of EfW when compared to wind as shown in Table 4. When aluminium recovery is included, EfW exhibits lower impacts in all categories with overall environmental benefits in three categories.

From this analysis it can be concluded that, in a future scenario where wind is considered to be the marginal source of power that is displaced by EfW, the advantages that EfW has over landfill will still apply. Replacing the selective non-catalytic reduction (SNCR) nitrogen oxides abatement technology used in the UK's EfW facilities with Selective Catalytic Reduction (SCR) technology would reduce the nitrogen oxides emissions leading to further improvements in the performance of EfW. This change should be evaluated fully in the future.

Recovering steel from EfW ash for recycling also improves the environmental performance of EfW, but to a lesser extent than aluminium recovery (Burnley et al.,
2015). The effect of steel recycling was not considered in this research because the SimaPro and WRATE life cycle inventories do not allow the impacts from electricity and heat consumption to be evaluated separately for steel manufacture and recycling. Therefore, it was not possible to evaluate the two energy supply scenarios in the same way as with aluminium recovery.

\subsection{LCA Comparisons of recycling and EfW}

Much research has been carried out on the comparative benefits of recycling and energy recovery from wastes under different conditions. However, an extensive search of the literature failed to find any analyses that considered a scenario where renewable energy is used in product manufacture and is displaced by the EfW. The following sections consider the situation for two combustible and recyclable components of MSW; waste newspaper and organic waste from kitchens and gardens for gas and wind-derived electricity.

\subsubsection{Newspaper}

There have been several studies on the comparative impacts of producing paper from primary resources and recovered waste paper. These tend to show that the environmental burdens are similar (Michaud et al., 2010) with neither alternative showing a clear-cut advantage. Table 6 confirms these findings in that, regardless of whether conventional or renewable sources of electricity and thermal energy are used in the processes, the differences between the impacts of primary and recycled production are small. This analysis does not include the highly location-specific environmental burdens of collecting the waste paper, operating the materials recovery facility (MRF) and transport of raw materials to the paper mill and products from the mill to the users. These impacts could have significant effects on the final results and should be evaluated for specific locations and recycling collection schemes.

For conventional energy use, manufacturing paper from recycled feedstock has the highest impacts for GWP and resource depletion and production from raw materials has the highest impacts in the other categories. When renewable energy sources are used, primary production still has lower climate change impacts, but recycling now has a greater impact in the eutrophication and toxicity categories. The increased eutrophication burdens for recycling arise in

TABLE 5: Life cycle burdens of producing one tonne of aluminium from raw materials and recovered aluminium using conventional and renewable energy sources.

\begin{tabular}{|c|c|c|c|c|c|c|}
\hline & GWP & $\begin{array}{c}\text { Resource depletion } \\
\text { kg Sb-eq }\end{array}$ & $\begin{array}{l}\text { Acidification } \\
\mathrm{kg} \mathrm{SO}_{2}-\mathrm{eq}\end{array}$ & $\begin{array}{c}\text { Eutrophication } \\
\mathrm{kg} \mathrm{PO}_{4}-\mathrm{eq}\end{array}$ & $\begin{array}{l}\text { Human toxicity } \\
\text { kg 1,4DB-eq }\end{array}$ & $\begin{array}{c}\text { Aquatic ecotoxicity } \\
\text { kg 1,4DB-eq }\end{array}$ \\
\hline \multicolumn{7}{|l|}{ Gas displaced } \\
\hline Primary production & 12000 & 70 & 56 & 20 & 57000 & 8200 \\
\hline Recycling & 400 & 3.2 & 2.4 & 2.3 & 1600 & 520 \\
\hline Saving from recycling (\%) & 97 & 95 & 96 & 89 & 97 & 94 \\
\hline \multicolumn{7}{|l|}{ Wind power displaced } \\
\hline Primary production & 5000 & 18 & 25 & 5.1 & 55000 & 5800 \\
\hline Recovered waste & 95 & 0.71 & 2.1 & 1.9 & 11600 & 470 \\
\hline Saving from recycling (\%) & 98 & 96 & 92 & 63 & 79 & 92 \\
\hline
\end{tabular}


TABLE 6: Environmental burdens of newsprint production from raw materials and reclaimed waste paper.

\begin{tabular}{|c|c|c|c|c|c|c|}
\hline & GWP & $\begin{array}{c}\text { Resource depletion } \\
\text { kg Sb-eq }\end{array}$ & $\begin{array}{l}\text { Acidification } \\
\mathrm{kg} \mathrm{SO}_{2}-\mathrm{eq}\end{array}$ & $\begin{array}{l}\text { Eutrophication } \\
\mathrm{kg} \mathrm{PO}_{4} \text {-eq }\end{array}$ & $\begin{array}{l}\text { Human toxicity } \\
\text { kg 1,4DB-eq }\end{array}$ & $\begin{array}{c}\text { Aquatic ecotoxicity } \\
\text { kg 1,4DB-eq }\end{array}$ \\
\hline \multicolumn{7}{|c|}{ Gas power and process heat } \\
\hline Primary production & 1300 & 9.1 & 6.7 & 3.2 & 720 & 500 \\
\hline Recovered waste & 1400 & 11 & 5.6 & 2.7 & 690 & 480 \\
\hline \multicolumn{7}{|c|}{ Wind power and biofuel process heat } \\
\hline Primary production & 230 & 1.7 & 2.6 & 0.66 & 410 & 110 \\
\hline Recovered waste & 260 & 1.5 & 2.2 & 1.3 & 470 & 200 \\
\hline
\end{tabular}

growing the biomass used for process heat generation and the aquatic toxicity burdens are caused by the disposal of the ash generated in producing the biomass-derived heat.

Whilst there are differences in the relative impacts of using raw materials and reclaimed paper, it should be noted that using wind power and biomass heat has lower impacts than using conventional energy sources in all categories for either given feedstock.

Comparing the two feedstocks may suggest that there is little benefit in recycling newsprint but, in order to obtain a full picture, recycling should be compared with other management options for the paper such as landfill and EfW. The environmental burdens of recycling paper or burning it in an EfW are included in Table 3 and the relative impacts are shown in Figures 3 and 4.

Regardless of the energy sources displaced by EfW and used in recycling, these results confirm the findings from previous studies and show that the LCA does not equivocally support either recycling or EfW. Considering the move from conventional to renewable energy does illustrate some trends. The overall climate change benefits of EfW no longer apply, although EfW still results in lower burdens than recycling. Recycling is now better for resource depletion (showing an overall benefit) and still maintains its advantages for acidification (with EfW showing both relative and absolute increases in burdens). Eutrophication burdens increase for both EfW and recycling with EfW now showing the lower impacts. For aquatic ecotoxicity, EfW moves to an overall benefit (due to the reduced metal emissions associated with the manufacture of wind power plant discussed in Section 3.1) while recycling no longer presents an overall benefit (again due to the biomass ash disposal impacts).

\subsubsection{Organic waste}

Although organic waste (the mixture of kitchen and garden waste) would never be regarded as an EfW feedstock in its own right, the principal non-landfill alternative to composting or digestion of kitchen and garden waste is to burn it in an EfW along with the other components of rMSW. This practice will become more common as restrictions on landfilling continue to be implemented. The LCA burdens for these options for conventional and renewable energy displacement are shown in the final three rows of Table 3.

The data in the SimaPro and WRATE LCA process inventories for waste composting do not permit the separation of the impacts and benefits associated with compost manufacture and use for the two electricity supply scenarios, so these results relate to the use of conventional fuels.
However, the quantities of fertiliser saved by composting are not large. According to WRATE, composting one tonne of organic waste displaces $1.6 \mathrm{~kg}$ of phosphate, $2.1 \mathrm{~kg}$ of potassium and $0.12 \mathrm{~kg}$ of nitrate fertilisers. Therefore, it is unlikely that changing the energy sources used in manufacturing these fertilisers will have a significant impact on the LCA results.

When conventional fuel is displaced by the EfW, this is the better option with respect to GWP, resource depletion and the two toxicity categories. NOx emissions from the EfW mean that composting is preferable in terms of acidification and eutrophication. With the move from gas to wind-derived electricity, Table 3 shows that the overall GWP and resource depletion benefits of EfW are eliminated and composting becomes the better option in these categories. Acidification and eutrophication have lower impacts with composting and both toxicity categories are better with EfW. The toxicity impacts of composting are due to the release of heavy metals from the compost when it is applied to the land. However, the data on metals in waste and compost taken from the WRATE database are now 25 years old and tighter environmental standards since that time, such as further restrictions on the use of heavy metals in packaging, may mean that applying compost to land has lower impacts than when the WRATE inventories were compiled. Further research is required to assess this issue.

Overall, these findings suggest that in the future when fossil fuelled energy production reduces, the case for composting food and garden waste rather than sending it to EfW becomes stronger.

\subsection{Normalised results}

The results presented above allow a direct comparison of the different waste management options for the three materials and the two energy supply scenarios, but they do not set the results in the wider context by providing a comparison of these impacts with the impacts associated with other human activities. The process of normalisation does this and can be carried out as an optional stage in the interpretation phase of an LCA. Normalisation presents each impact as either a proportion of that impact produced by the total population of a geographical area or that impact produced by a typical person living in a particular area. The results of this study were normalised by comparing the impacts to those of a typical citizen of the European Union and are shown in Table 7. 


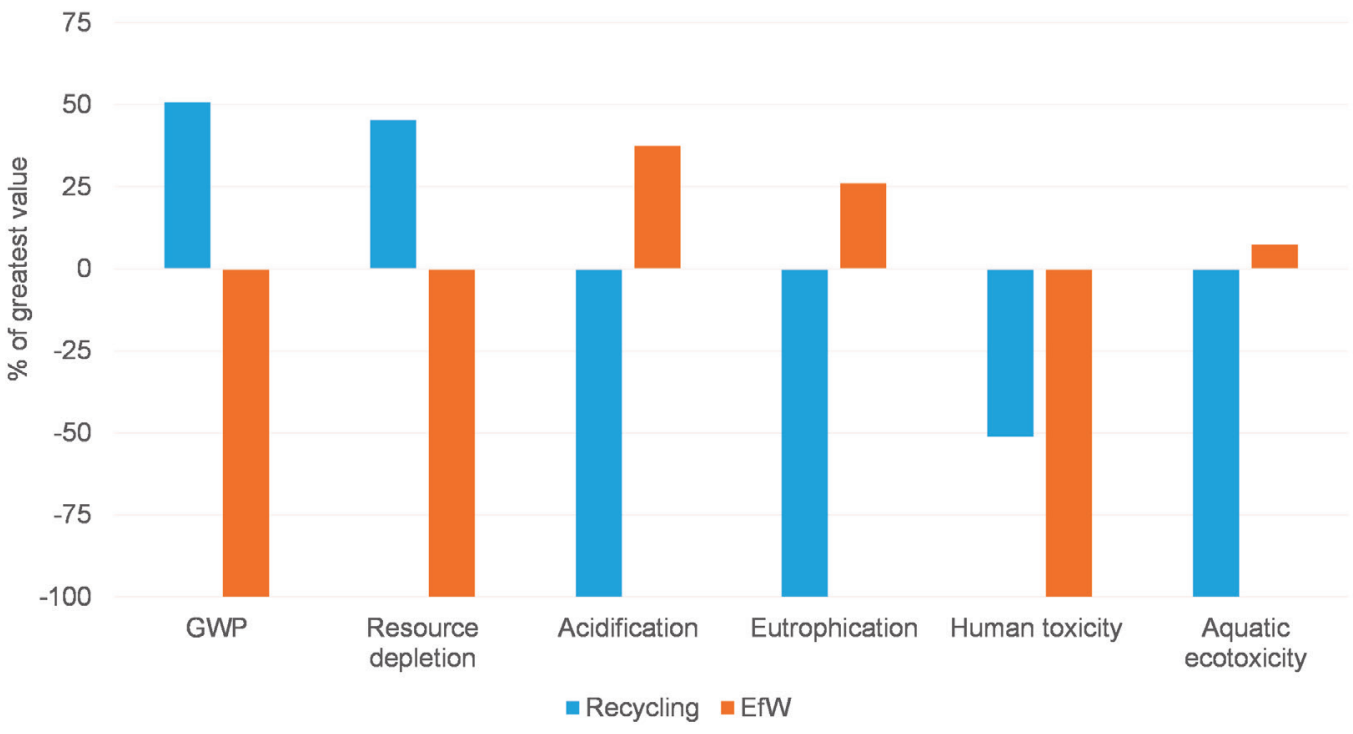

FIGURE 3: Comparison of recycling and EfW of newspaper - gas power replaced by EfW and used in the recycling process.

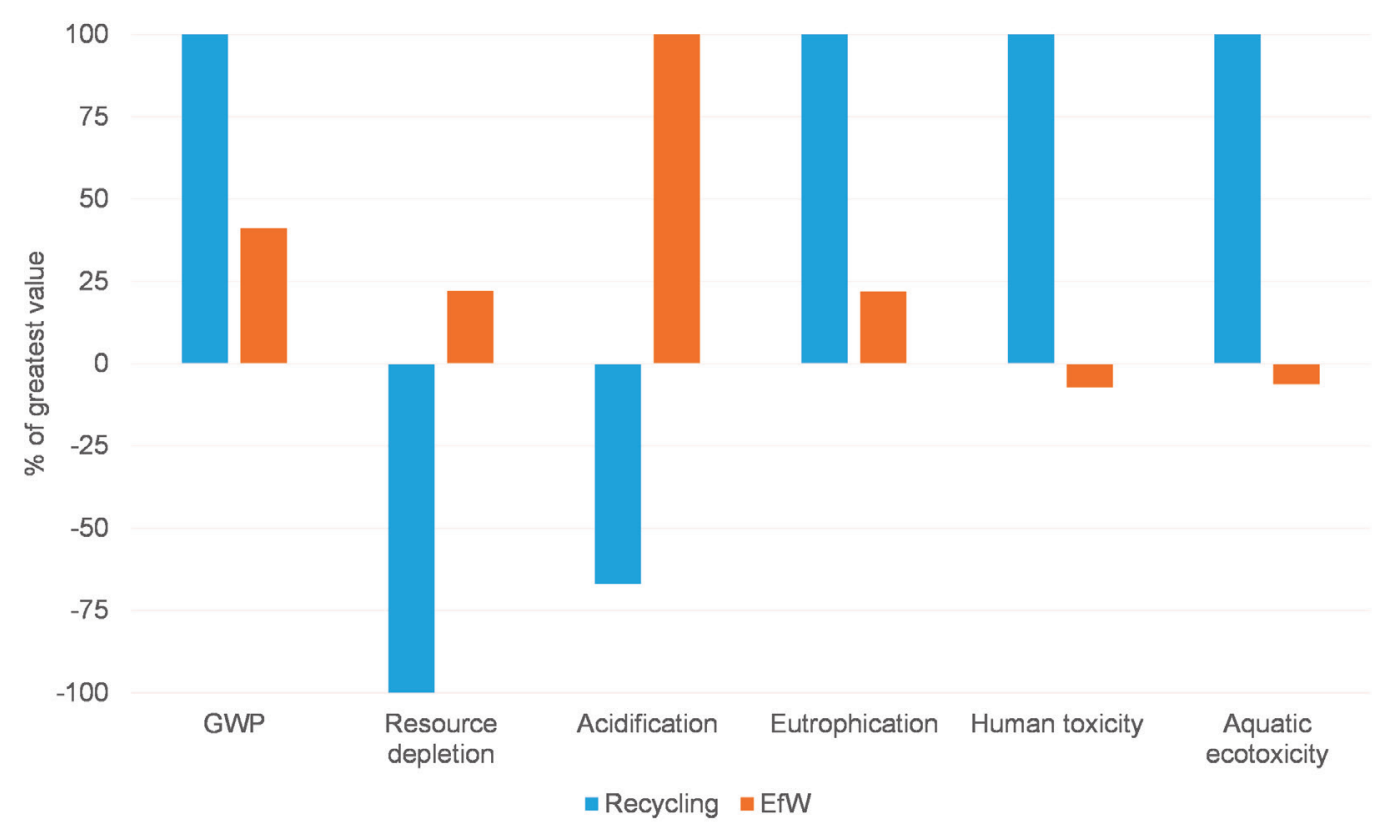

FIGURE 4: Comparison of recycling and EfW of newspaper - wind power replaced by EfW and used in the recycling process.

Taking the United Kingdom as an example, in 2017 the population of 66 million (ONS, 2018) produced 15.2 million tonnes of rMSW or 0.23 tonnes per person per year (Defra, 2018). The values shown in Table 7 relate to one tonne of each material, so considering rMSW, the category that makes the highest contribution to a person's overall impact is the $1.6 \%$ of their eutrophication burden resulting from the landfill of the rMSW. Corresponding values for the other impacts are shown in Figure 5.

Figure 5 demonstrates that, regardless of the rMSW management option selected or energy supply scenario, the contribution to a person's environmental footprint is very low. However, these findings do not suggest that fur- ther action to improve the situation is unnecessary, rather they indicate the priorities for action that should be considered by policymakers and regulators. These priorities are:

Further reduce the reliance on landfill, particularly as the carbon intensity of power generation continues to decline.

Reduce the GWP emissions from EfW through increasing the thermal efficiency of EfW, moving from the UK's predominant power-only to combined heat and power (CHP) EfW and reducing the fossil carbon content of rMSW through improved plastic separation from MSW.

Reduce the NOx emissions from EfW by the adoption of SCR which account for the acidification, eutrophication and 


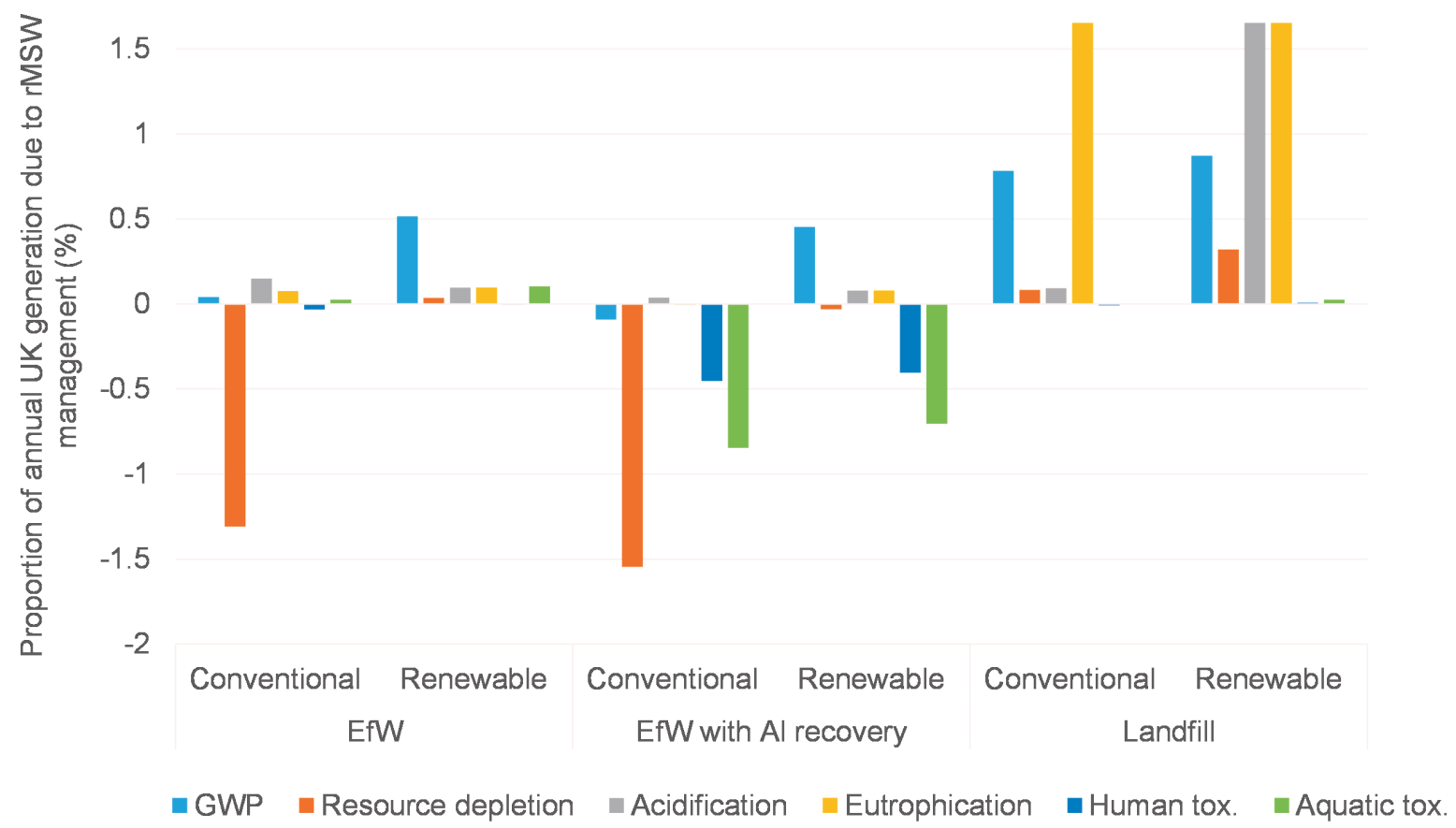

FIGURE 5: Contribution to an individual's total impacts from the management of their rMSW (Euro persons equivalent).

toxicity burdens.

The results from the normalisation stage of an LCA cannot be used to show that any particular impact category is of more or less significance than any other category. To do so the "Weighting" stage of the LCA, which allows the importance of each of the impact categories to be estimated, is required. However, the weighting factors selected can be subjective and are described as "not scientifically based" by the ISO (BSI EN ISO, 2006). Therefore it was concluded that a detailed weighting assessment would be more appropriate as the subject of a subsequent study.

\subsection{Sensitivity Analysis}

All LCA studies are liable to several sources of uncertainty. For example, the factors used to characterise the environmental impacts of different emissions and the reliability and currency of the inventories of process emissions. Waste management LCAs suffer from all these issues and also from questions over the composition of the various waste streams, the sources of energy used and displaced by EfW processes and the effectiveness and impacts of recycling operations. A detailed sensitive analysis (SA) is beyond the scope of this preliminary paper, but an initial investigation of the sensitivity to the following was carried out and the results are shown in Figure 6.

The aluminium content of the UK's rMSW is $1.3 \%$ (Defra, 2009) and it was initially assumed that $50 \%$ of this would be recovered from the EfW residues. In the future, as the segregation of materials from waste for recycling improves, the amount remaining in the rMSW may fall. Equally, the efficiency of the processes that remove aluminium from the ash may improve over time. Figures 6 a and $b$ consider the sensitivity of the rMSW EfW process to aluminium recovery for renewable and gas-fired power respectively. In the renewable power case, for most impacts, changing the proportion of aluminium recovered has little effect. For GWP, if no aluminium recovery takes place, there is a $16 \%$ increase in the impact. It should be stressed that the absolute reduction in aluminium recovery in this case would be $6.5 \mathrm{~kg}$ per tonne of waste burned, reflecting the high GWP impact of Al production as shown in Table 5. The human toxicity impacts are highly sensitive to aluminium recovery due to the reduction in poly aromatic hydrocarbon (PAH) emissions when the aluminium produced from virgin sources is displaced by recycled aluminium. When conventional power sources are displaced (Figure $6 \mathrm{~b}$ ), the position is similar for most impacts, but the GWP change when aluminium recovery is not carried out is $140 \%$. This is caused by the large reduction in $\mathrm{CO}_{2}$ emissions achieved by recycling aluminium as shown in Table 5 .

Figure $6 \mathrm{c}$ shows the sensitivity of the impacts to the percentage of the power displaced coming from renewable sources. Again, most classes of impacts show little sensitivity to this factor. However, the GWP impacts increase as the proportion of power coming from renewable sources increases. Wind power is virtually carbon-free so displacing this source with EfW (where a proportion of the carbon emissions are of fossil origin) results in increased emissions. When $100 \%$ of the displaced energy is generated from gas, EfW shows an overall GWP benefit, but this is reduced to zero when $17 \%$ of the energy is from renewable sources. Resource depletion follows a similar trend with the benefits achieved from reducing gas consumption reducing as the proportion of resource-free wind power displaced increases. 
TABLE 7: Normalised results (Euro persons equivalent per tonne managed).

\begin{tabular}{|c|c|c|c|c|c|c|c|}
\hline & & GWP & $\begin{array}{l}\text { Resource } \\
\text { depletion }\end{array}$ & Acidification & Eutrophication & $\begin{array}{l}\text { Human } \\
\text { toxicity }\end{array}$ & $\begin{array}{l}\text { Aquatic } \\
\text { ecotoxicity }\end{array}$ \\
\hline \multicolumn{8}{|c|}{ Gas and conventional heat displaced and used in recycling/manufacture } \\
\hline \multirow[t]{3}{*}{ rMSW } & EfW & 0.002 & -0.06 & 0.007 & 0.003 & -0.001 & 0.001 \\
\hline & EfW with Al recovery & -0.004 & -0.07 & 0.002 & -0.0002 & -0.02 & -0.04 \\
\hline & Landfill & 0.03 & 0.004 & 0.004 & 0.07 & -0.0004 & -0.0001 \\
\hline \multirow[t]{2}{*}{ Paper } & Recycling & 0.02 & 0.04 & -0.02 & -0.01 & -0.001 & -0.02 \\
\hline & EfW & -0.03 & -0.08 & 0.006 & 0.003 & -0.003 & 0.001 \\
\hline \multirow[t]{2}{*}{ Organic waste } & Composting & 0.0005 & 0.002 & 0.002 & 0.004 & 0.001 & 0.003 \\
\hline & EfW & -0.007 & -0.02 & 0.008 & 0.004 & 0.0004 & 0.002 \\
\hline \multicolumn{8}{|c|}{ Wind and renewable heat displaced and used in recycling/manufacture } \\
\hline \multirow[t]{3}{*}{ rMSW } & EfW & 0.02 & 0.002 & 0.008 & 0.004 & -0.0002 & 0.004 \\
\hline & EfW with Al recovery & 0.02 & -0.001 & 0.006 & 0.003 & -0.02 & -0.03 \\
\hline & Landfill & 0.04 & 0.01 & 0.005 & 0.07 & 0.0004 & 0.001 \\
\hline \multirow[t]{2}{*}{ Paper } & Recycling & 0.003 & -0.006 & -0.005 & 0.02 & 0.003 & 0.07 \\
\hline & EfW & 0.001 & 0.001 & 0.008 & 0.004 & -0.0002 & -0.004 \\
\hline \multirow[t]{2}{*}{ Organic waste } & Composting & 0.0005 & 0.002 & 0.002 & 0.004 & 0.001 & 0.003 \\
\hline & EfW & 0.001 & 0.002 & 0.008 & 0.004 & 0.0008 & -0.001 \\
\hline
\end{tabular}

Considering the power source in relation to paper recycling (Figure $6 \mathrm{~d}$ ) shows that the GWP and resource depletion impacts reduce with increasing use of wind power. This is because paper recycling consumes more energy than manufacturing from raw materials (Table 6). With respect the two toxicity categories, there is an increase in the impacts as the proportion of renewable energy increases with a net contribution to the impact occurring at $21 \%$ and $30 \%$ renewable energy for aquatic and human toxicity respectively. As discussed in Section 3.1, the toxicity impacts associated with wind power relate to the emissions during manufacture of the steel components of the wind turbines.

\section{CONCLUSIONS AND RECOMMENDATIONS}

This research has investigated the life cycle impacts of managing rMSW, waste newspapers, and kitchen/garden waste. Two scenarios were considered. In the first, natural gas is the marginal source of electrical energy that is displaced by EfW and used to power manufacturing and recycling processes. In the second scenario, wind energy is displaced by EfW and used to provide process power with process heat supplied by burning biomass.

The results primarily refer to the situation in the UK, but give an indication of the likely position in other developed countries, particularly other western European nations. The impact categories selected are widely used in the UK in

a.

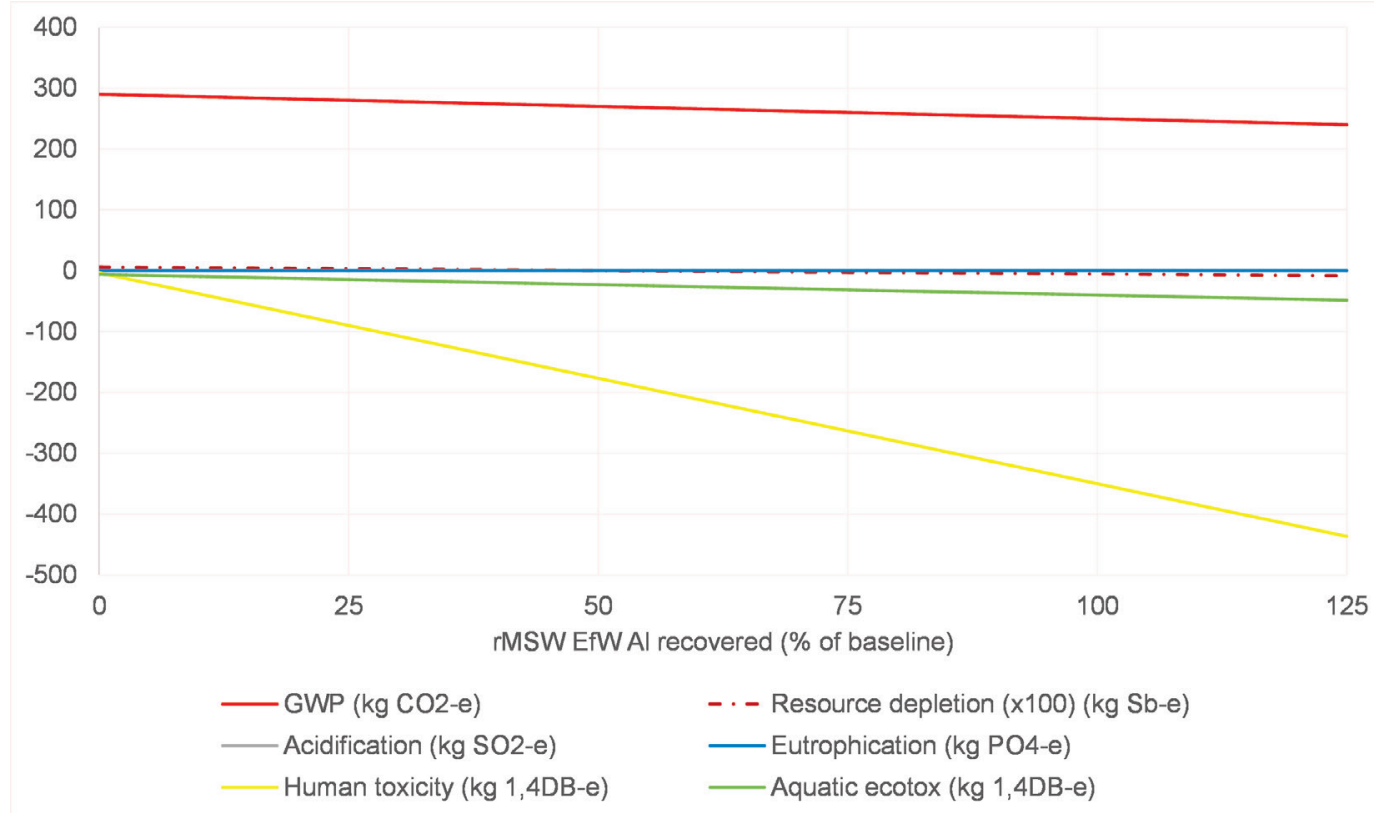


b.

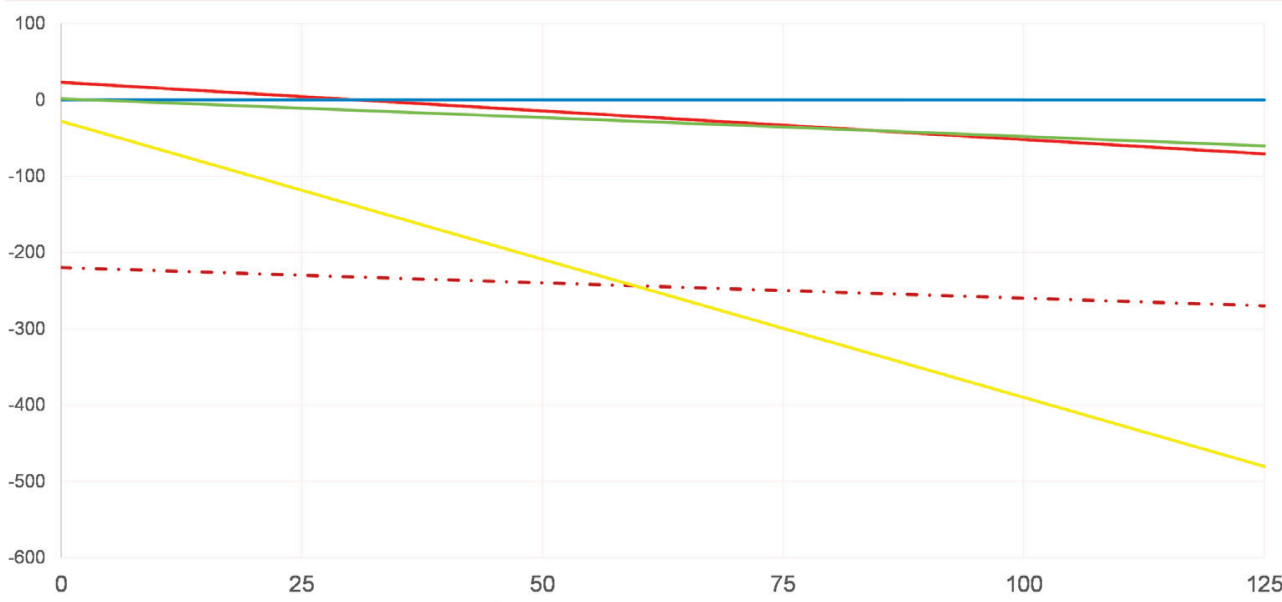

rMSW EfW Al recovered (\% of baseline)

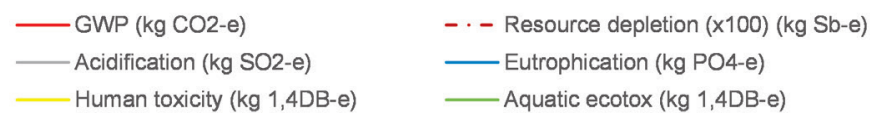

C.
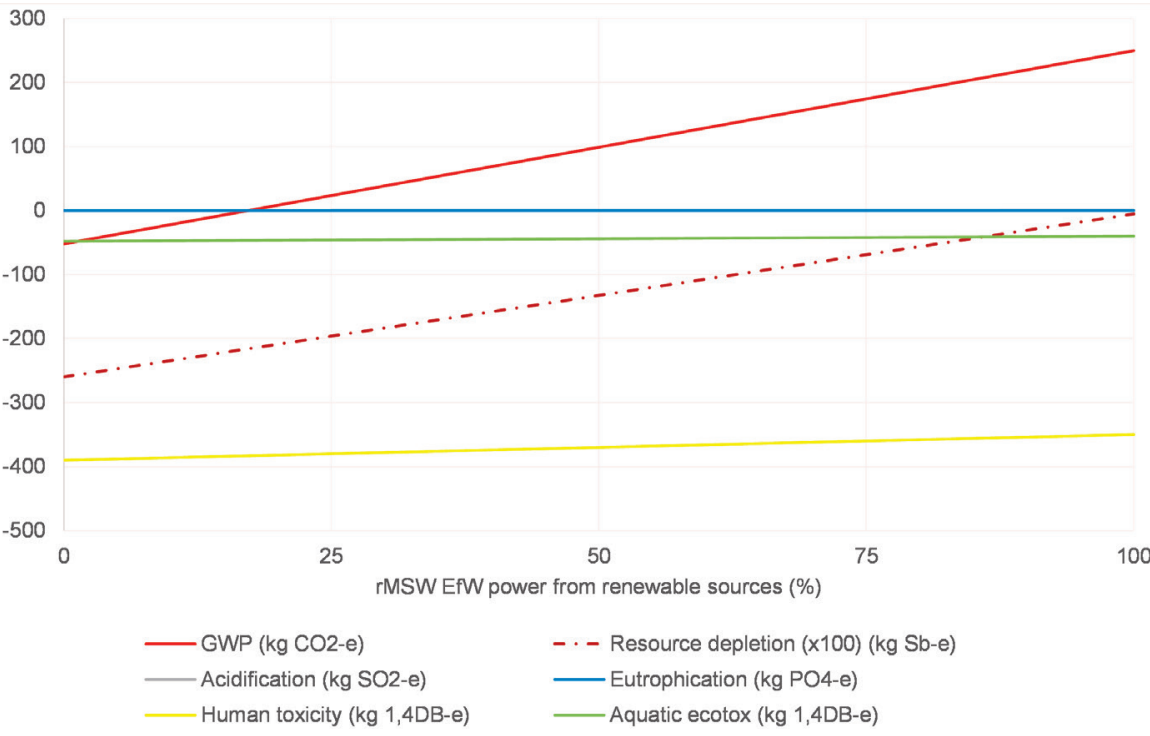

d.

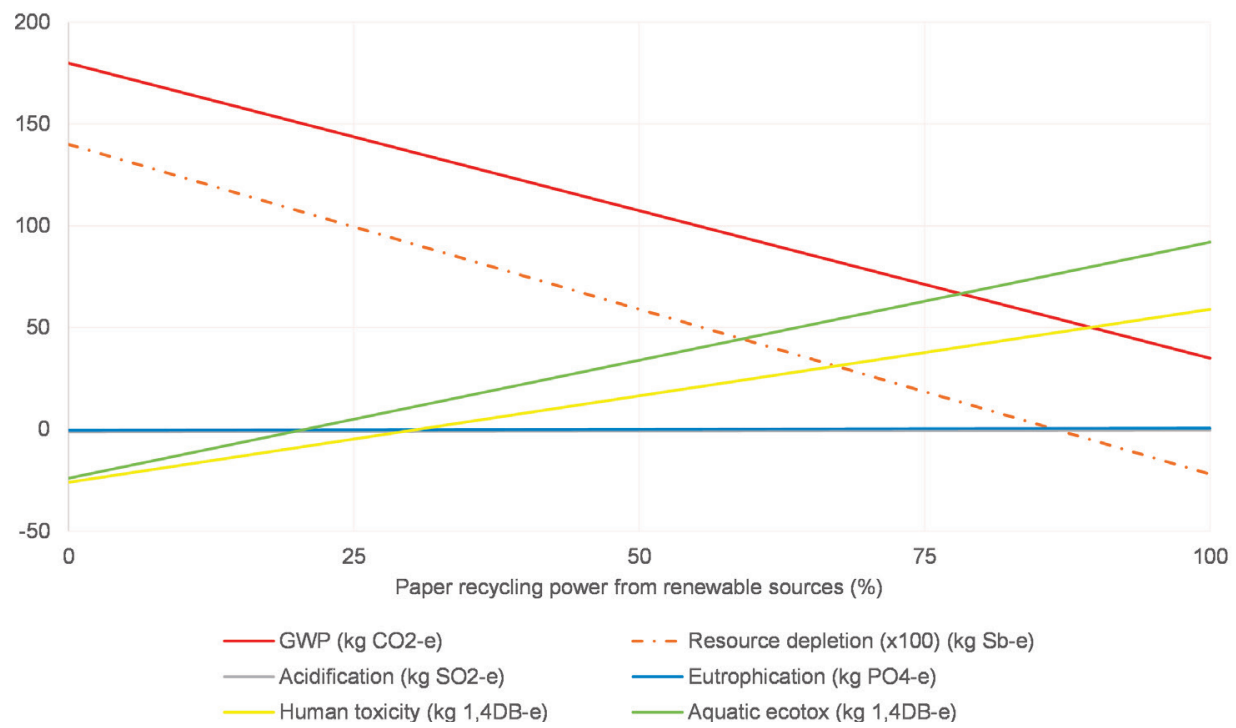

FIGURE 6: Sensitivity analysis: a. Al recovery - rMSW to EfW (wind power) / b. Al recovery - rMSW to EfW (gas power) / c. Percentage of power from wind - rMSW to EfW / d. Percentage of power from wind - paper recycling. 
waste-related LCAs. Therefore it would be of value to carry out similar studies using the energy supply and waste composition of a selection of countries and impact categories that are used more widely.

Wind power is generally less polluting than gas, coal or rMSW derived electricity, but there is a notable exception for human and aquatic ecotoxicity impacts. In the former category, wind power has higher impacts than rMSW due to the emissions of chromium and arsenic to the atmosphere during manufacture of the plant. For aquatic ecotoxicity, wind power has a greater impact than gas due to the emissions of nickel, cobalt and beryllium to water during manufacture.

When gas power is displaced, treating rMSW by EfW has lower impacts than landfill in terms of GWP, resource depletion, eutrophication and human toxicity whilst landfill has lower impacts in the acidification and aquatic ecotoxicity categories. With a move to wind power, EfW has the lowest impacts in all categories apart from acidification. When the environmental benefits associated with recycling aluminium reclaimed from the EfW ash are taken into account, EfW is the better option regardless of the source of power displaced. Therefore EfW should continue to be promoted as a better option even with the reducing carbon intensity of conventional power generation.

Comparing the management of waste newspapers by recycling and EfW with gas as the marginal fuel shows that EfW is the better option considering GWP, resource depletion and human toxicity and recycling is the better option in the other impact categories. When wind power is displaced, EfW has lower impacts in all categories apart from acidification. This analysis does not include the impacts associated with collecting the paper and transporting raw materials and products which could be significant.

When comparing composting and EfW of organic waste, displacing gas shows that GWP, resource depletion and the two toxicity categories have lower impacts for EfW, there is no difference for eutrophication and acidification potential is lower for composting. When wind power is displaced, composting becomes the better option for GWP and resource depletion.

Normalisation of the results shows that rMSW management accounts for a relatively small proportion of the average citizen's environmental impact and helps to clarify the priorities for future action by the waste and resources management industry.

In summary, as the carbon intensity of electricity and heat production are reduced, there is no systematic change in the LCA impacts of managing these waste fractions. For waste paper and organic waste, recycling is preferable to $\mathrm{EfW}$ in some impact categories while $\mathrm{EfW}$ is preferable in others. Regardless of the marginal power source, treating rMSW by EfW is preferable to landfill, particularly when aluminium is recovered from the EfW ash for recycling. There is some evidence to suggest that in a low carbon power scenario, composting has advantages over EfW for organic waste.

Further work should be carried out in this area to:

- Re-assess the LCA impacts of wind power using the most up to date information on the materials used in their construction, their lifespan and end-of-life fate to determine the effect that this has on the toxicity impacts.

- Determine the LCA impacts of managing waste newsprint for both energy scenarios while taking account of the impacts associated with collecting and transporting the waste and products

- Determine the individual or combination of sources of renewable and nuclear power that will collectively represent the marginal supply in a low carbon future and determine the LCA impacts of EfW, materials recycling and composting under these conditions.

- Compare the LCA impacts of EfW for SNCR and SCR NOx abatement systems.

- Re-assess the impacts of organic waste composting using more up to date information on the heavy metal content of the wastes.

- Evaluate the effect of using more-advanced nitrogen oxides abatement technologies on the LCA impacts of EfW.

- Carry out a similar study applying the waste composition and power production scenarios from a selection of countries.

\section{REFERENCES}

Bates J., 2009. Impacts of managing residual municipal waste. In: Patel N (ed) Accomplishments from IEA bioenergy task 36: integrating energy recovery into solid waste management systems (20072009). International Energy Agency, Paris.

BS EN 16760, 2015. Bio-based products - life cycle assessment. British Standards Institution, London, UK.

BS EN ISO 14040, 2006. Environmental management - Life cycle assessment - Principles and framework. British Standards Institution, London, UK.

Burnley S.J., Coleman T., Peirce A., 2015. Factors influencing the life cycle burdens of the recovery of energy from residual municipal waste. Waste Manage., 39, 295-304.

Burnley S.J., Boardman C.P., 2017. The use of dynamic life cycle assessment to evaluate the long term climate change impacts of waste management processes, 16th International Waste Management and Landfill Symposium, Cagliari, Italy.

Christensen T.H., Gentil E., Boldrin A., Larsen A.W., 2009. C balance, carbon dioxide emissions and global warming potentials in LCA-modelling of waste management systems, Waste Manag. Res., 27(8), 707-715.

Classen M., Althaus H.-J., Blaser S., Doka G., Jungbluth N. and Tuchschmid M. (2009) Life Cycle Inventories of Metals. Final report ecoinvent data v2.1 No.10. Swiss Centre for Life Cycle Inventories, Dübendorf, $\mathrm{CH}$.

Department for Business, Energy and Industrial Strategy (DBEIS), 2018. Implementing the end of unabated coal by 2025 , DBEIS, London, UK.

Department for Environment, Food and Rural Affairs (Defra), 2009. Municipal Waste Composition, Report WRO199, Defra, London.

Department for Environment, Food and Rural Affairs (Defra), 2018, UK statistics on waste, Defra, London, UK.

Ecoinvent, undated, Reports on ecoinvent 2, https://www.ecoinvent.org/database/older-versions/ecoinvent-version-2/reports-on-ecoinvent-2/reports-on-ecoinvent-2.html (Accessed 30 January 2019).

ELDC, 2010, European Commission Joint Research Centre, http://eplca.jrc.ec.europa.eu/ELCD3/ (Accessed 30 January 2019).

European Commission (undated) European Commission Environment Circular Economy, http://ec.europa.eu/environment/circular-economy/index_en.htm (Accessed 30 January 2019)

European Environment Agency, 2018. Annual European Union greenhouse gas inventory 1990-2016 and inventory report 2018, European Commission, DG Climate Action European Environment Agency, Brussels, Belgium. 
Finnveden G., Hauschild M.Z., Ekvall T., Guinee J., Heijungs R., Hellweg S., Koehler A., Pennington D., Suh S., (2009). Recent developments in life cycle assessment. J. Environ. Manage. 91, 1-21.

Frischknecht R., Jungbluth N., Althaus H-J., Doka G., Dones R., Heck T., Hellweg S., Hischier R., Nemecek T., Rebitzer G., Spielmann M., 2005. The Ecoinvent database: Overview and methodological framework. Int J Life Cycle Assess. 10(1), 3-9.

Guinée J.B. (ed), 2002. Handbook on life cycle assessment, Kluwer Academic publishers, Dordrecht, The Netherlands.

Hadzic A., Voca N., Golubic S., 2018. Life-cycle assessment of solid-waste management in city of Zagreb, Croatia, J. mater. cycles waste, 20(2), 1286-1298

Hischier R. (2007) Life Cycle Inventories of Packaging and Graphical Paper. Final report ecoinvent data v2.0 No. 11. Swiss Centre for Life Cycle Inventories, Dübendorf, $\mathrm{CH}$.

Kjeldsen P., Barlaz M.A., Rooker A.P., Baun A., Ledin A., Christensen T.H., 2002. Present and long-term composition of MSW landfill leachate: A review, Crit. Rev. env. sci. tec., 32(4), 297-336.

Maalouf A., El-Fadel M., 2018. Carbon footprint of integrated waste management systems with implications of food waste diversion into the wastewater stream, Resour. Conserve. Recy., 133, 263-277.

Michaud J-C., Farrant L., Jan O. (2010). Environmental benefits of recycling - 2010 update. Waste and Resources Action Programme, Banbury, UK.
Office for National Statistics (ONS) (2018), Population estimates for the UK, England and Wales, Scotland and Northern Ireland: mid2017, Office for national Statistics, London, UK.Defra, 2018

Ozoemena, M., Cheung, W.M., Hasan, R., 2018. Comparative LCA of technology improvement opportunities for a $1.5 \mathrm{MW}$ wind turbine in the context of an onshore wind farm, Clean technol. Envir., 20(1). 173-190.

Paraskevas, D., Kellens, K., Van de Voorde, A., Dewulf, W., Duflou, J.R., 2015. Environmental impact analysis of primary aluminium production at country level, Procedia CIRP 26, 455-460, 13th Global Conference on Sustainable Manufacturing - Decoupling Growth from Resource Use.

Razdan P., Garrett P., 2015. Life cycle assessment of electricity production from an onshore V110-2.0 MW wind plant, Vestas Wind Systems, Aarhus, Denmark.

Schott S., Bernstad A., Wenzel H., Jansen J., 2016. Identification of decisive factors for greenhouse gas emissions in comparative life cycle assessments of food waste management - an analytical review, J. Clean. Prod., 119, 13-24.

Villanueva A, Wenzel H., 2007. Paper waste recycling, incineration or landfilling? A review of existing life cycle assessments, Waste Manage. 27(8), S29-S46. 